\title{
EENE OUDJAVAANSCHE VERTALING VAN INDISCHE SPREUKEN
}

DOOR

Dr. H. H. JUYNBOLL.

Er zijn twee Oudjavaansche prozageschriften, die den titel Sârasamuccaya voeren. Het eene is een wetboek, waarvan de Leidsche Universiteitsbibliotheek drie HSS. bezit (cod. 3407a, $3458 \mathrm{~m}$ en 3697). Het andere is een tutur of zedekundig geschrift, bestaande uit Indische spreuken, gevolgd door eene Oudjavaansche vertaling. Ook hiervan vindt men drie HSS. in de Leidsche bibliotheek (cod. $3458^{\mathrm{i}}, 3458^{\mathrm{k}}$ en $3458^{\mathrm{l}}$ ). De meeste dezer spreuken zijn aan het Mahâbhârata ontleend, niet alleen aan de parwan's wier O. J. vertaling bewaard gebleven is, als het $\hat{A} \mathrm{di}$ - en het Ud yogaparwan, doch ook aan parwan's, wier O. J. vertaling reeds in Friederich's tijd verloren gegaan was, b.v. het Anuçâsana- en het Açwamedhaparwan. Daar de aangehaalde Sanskritverzen door vergelijking met het Mahâbhârata of met Böhtlingk's Indische Sprüche meestal te herstellen zijn, voor zoover zij corrupt zijn, en de Oudjavaansche vertaling meestal vrij nauwkeurig is, is dit geschrift uit een lexicographisch oogpunt niet van belang ontbloot. Ter nadere kenschetsing laten wij er hier eenige uittreksels uit volgen.

In het begin leest men, hoe bhagawân Wararuci de sâra (quintessens) van de aṣṭâdaça parwwa (d. i. het Mahâbhârata) verzamelde: Bhagawân Wararuci mupulakĕn sâra-sâra sang hyang Aṣtâdaçaparwwa, gawe bhagawân Byâsa. Hierbij wordt een Sanskritvers aangehaald, dat men terug vindt in het Âdiparwan, cloka $2328^{\mathrm{b}}$ en $2329^{\mathrm{a}}$ :

Yathâ samudro hi mahân yathâ ca Himawân girị̣, ubho ratnawidhi ${ }^{1}$ kyato tathâ Bhâratam ucyate.

1 Lees nidhî. 
In het Âdiparwan staat echter:

yathâ samudro bhagawân yathâ Merur mahâgiriḥ ubhau khyâtau ratnanidhî tathâ Bhâratam ucyate.

Hieruit ziet men, dat de Calcutta-editie hier afwijkt van den tekst, dien de O. J. vertaler gebruikt heeft; de O. J. vertaling ervan luidt: Nihan kottaman ira, kadyangga ning tasik lâwan gunung Himawân, an kalyan mâs maṇi sarwwa mûlya, mangkana ta sakweh ning aji, Bhâratakathâ ginawe nira.

De bedoeling, dat het Mahâbhârata een juweelkistje genoend en met den oceaan en den Meru vergeleken wordt, is dus door den O. J. vertaler begrepen.

Eenige regels verder wordt een dergelijk vers aangehaald, dat eveneens de strekking heeft, om de voortreffelijkheid van het Mahâbhârata te betoogen, en dat men ook in het Âdiparwan vindt (çloka 647):

Çrutwâ twidam upâkyânam, çrawyam anyan na rodhyate ${ }^{1}$, pungskokilarutaṃ çrutwâ rukṣâ dhwângkṣasya wâg iwa.

Dit vers luidt in de Calcutta-editie evenzoo, behalve dat men daar in plaats van rutam leest: giram. De O. J. vertaling hiervan is: Yan hana sira tlas rumĕngö rasa niki sang hyang aji, pisaningu juga sirâhyuna rumĕngwa kathântara, tĕkâ ring gita weṇu winadi, kadyangga ning wwang rumĕngö suçabda ning kuwong, huwus rumĕsĕp ri hati langĕn ing swaranya, amangun harṣa ning citta, tau hana ganti nikâhyuna rumĕngwârĕs ning çabda ning gagak.

Ook hier is de bedoeling van den schrijver door den vertaler begrepen. Tevens blijkt uit de vertaling, dat pisaningu moet beteekenen: "hoe zou" en tan hana ganti: "er is geen kans."

Wenden wij ons thans tot den eigenlijken inhoud, dan zien wij bv. op pag. 5 van cod. $3458^{1}$ een Sanskritvers aangehaald, dat men bijna woordelijk terugvindt in $n^{\circ} 5134$ van Böhtlingk's Indische Sprüche :

Yathâ yathâ hi puruṣaḥ kalyâṇe ramate manaḥ, tathâ tathâsya sidhyanti sarwârthâ nâtra sang çayah.

Bij Böhtlingk leest men in plaats van ramate (verheugt zich): kurute en in plaats van sidhyanti sarwârthâ staat: sar-

1 Lees rocyate. 
wârthâh sidhyante. De O. J. vertaling hiervan luidt: Salwiraning wwang kaniș̣a madhyamottama tuwi, yâwat gawai hayu kajĕněk ni hatinya, niyata siddha ning sasinadhyanya.

Bij vergelijking hiervan met Böhtlingk's Duitsche vertaling zal men zien, dat er geen groot verschil tusschen beide bestaat, behoudens de uitweiding van den O. J. vertaler, die ter verklaring van salwiraning (een ieder die) er nog bijvoegt: kaniṣṭa madhyamottama tuwi. Dit vers is ontleend aan het Udyogaparwan (Mahâbhârata, V, 1223).

Een vers uit hetzelfde parwan (1513 b en 1514 a) wordt aangehaald op pag. 6 van cod. 34581 (vgl. Böhtlingk's Indische Sprüche 1628);

Kântâre wanadurgeṣu kṛcchrâswâpatsu sambhrame, udyateṣu ca çastreṣu nâsti dharmawatâm bhayaı̣.

In het Indische origineel leest men in plaats van $\mathrm{d} h$ a r m a w a ta m (van deugdzamen): sattwawatâm. Dat hier echter werkelijk het eerste woord bedoeld is, blijkt uit de $\mathrm{O}$. J. vertaling: Ri hlět, ring alas, ring pringga, ring laya, salwir ning duḥkahetu, paprangan kunang, tar tka juga ikang bhaya ri sang dharmika.

Deze vertaling geeft wel in hoofdzaak den inhoud weer, doch is toch niet geheel juist. Kântâra bv., door Böhtlingk vertaald met "Urwald" is iets anders dan het O.J. hĕlĕt, dat "tusschenruimte" beteekent. Waarschijnlijk heeft de vertaler gedacht aan a ntara.

Niet alleen spreuken uit het Mahâbhârata, doch ook uit andere werken vindt men in deze verzameling. Zoo wordt op pag. 7 van cod. $3458^{\mathrm{l}}$ een vers uit het Pañcatantra (ed. Kosegarten I, 181) aangehaald (vgl. Indische Sprüche 4.179):

Pârwe wayasi yạ̣ çântaḥ sa çânta iti me matị̣

dhâtuṣu ksîyamâneṣu çamaḥ kasya na widyate.

In plaats van widyate heeft de Indische tekst jâyate. De O. J. vertaling luidt: Ikâng upasaman rarai tikang sinanggah upaçama, âpan jâti ng upaçama an katkan tuha, ri kșaya ning dhâtu ngke ring çarira. Deze vertaling is juist.

Ook verzen uit den Hitopadeça vindt men hier angehaald, bv. III, 85 (ed. Schlegel) of Indische Sprüche 5514:

Yuwaiwa dharmaçîlạ̣ syâd anityam khalu jîwitam, ko hi jânâti kasyâdya mṛtyusenâ patiṣyati.

Hier is het verschil met den Indischen tekst grooter, want 
daar staat in plaats van mṛtyusena patiṣyati (het leger van den dood zal overvallen): mṛtyukâlo bhawiṣyati (het zal de tijd van den dood ziju). Dit komt meer overeen met de O J. vertaling: Mangkenya rarai ta pwa kita'n lěkasa gawai dharmmasâdhana, âpan anitya iking hurip, syapa kari wruha ri tĕka ning pati, syapa kawruhana tĕka ning patinya wih.

Hier geeft de vertaler dus den laatsten regel van het vers op twee verschillende manieren weer.

Soms treft men hier spreuken aan, waarvan alleen het begin elders voorkomt, b.v. op p. 18 :

A hingsâsatyawacanam sarwwabhûteșu cârjawam, kṣamo caiwâpramâdaç ca yasyaite sasuk(h)î bhawet.

Dit herinnert aas Ind. Spr. 823 of M. Bh. XIII, 6414:

A himisâsatyawacanaṃ sarwabhûtânukampanam, çamo dânaṃ yathâçakti gârhasthyo dharma uttamạ̣.

De O. Jav. vertaling van het boven aangehaalde vers luidt: Ahingsâ, satya, si tan kira-kira kahalâ ning sarwwa prâṇ̂, si klân(ta), si tan palěh-palěh, sang makadṛbya ikâ kabaih, sira prasiddha ning suka ngaran ira.

Hier is tan palěh-palěh de O. J. vertaling van het Skr. apramâda (bedachtzaamheid). In het O. Jav. Râm. III, 65 wordt palĕpalĕh in het Balin. verkeerd weergegeven met hampura (vergeven): Wadwâ doṣanya palěpalĕh, is "een leger dat zich aan plichtverzuim schuldig maakt." Op een andere plaats van hetzelfde gedicht (XXIV, 24) heeft de Balin. vertaling jangka-jangka, waarvan de beteekenis onbekend is: Yadi'n palĕh-palĕh pilih kita pulih panumpala nikâkunĕng mamĕnanga, indien gij echter soms onachtzaam zijt, dan zal het einde zijn dat hij overwint. De woorden palěh, pilih en pulih, die elkaar opvolgen, zijn een voorbeeld van alliteratie.

In het volgende vers uit het Pañcatantra, dat ook in de Indische spreuken voorkomt (3549) wijkt ook het slot af van de editie van Kosegarten. Het staat hier op p. 46:

Nâce(h)âdayati kopînaṃ na dangçamaçakâpaham, çunạ̣ pucc(h)am iwânarthạ̣ jũânam anyây a wartinaḥ.

In de editie luidt dit vers (III, 98):

Nâcehâdayati kaupînaṃ na dạ̣çamaçakâpaham. çunaḅ puccham iwa wyarthạ̣ pạṇ̣ityạ̣ dharmawarjitam. 
Zeer uitvoerig is de O. J. vertaling: Yadyapin sang hyang samyagjñâna kawruhan ikang wwang duççila, wyarthâ ta rakwa sira, âpan tan wnang sira manĕkâkĕn ing swasâdhya, ya tan rinakșa ring çiștâcâra, kadyanggâ nîkû ning ș̣gâla, tan panaputi, tan kupina, tan pamurud dangça maçaka, alu lalĕr, adi, mangkana ta sang hyang samyagjñana, an ungguh irikang wwang dúççîla.

Hier heeft blijkbaar de O. J. vertaler het Skr. woord ka upîna (schaamdeel) niet begrepen en gedacht aan het O. J. kopina in den zin van schaamgordel, zooals het o. a. in den Tantu Panggĕlaran voorkomt. A di is hier het Skr. âdi in samenstellingen en beteekent dus: enzoovoorts.

Op dezelfde pagina wordt M.Bh. XII, 6760 angehaald, doch eenigszins gewijzigd:

Yathâ dhenusahasreșu watso windati mâtaram. tathâ çubhâçubhạ̣ karmma karttâram anugacc(h)ati.

In het M.Bh. XII, 6760 en Pañcatantra II, 134, (ed. Koseg.) staat in plaats van çubhâçubham (goed of slecht) pûrwakṛt am (vroeger verricht). Dit komt meer overeen met de O.J. vertaling, die luidt: Tatan anggâ tan kabhuktya ikang pûrwwakarmmaphala de nikang makakarmma ya, mwang tan kemuran dumunung irikang karttâ ngûni, kadi krama nikang anak ning lěmbu tan kemuran umet kawwîtanya, yadyan mâtusa ikang lĕmbu sḍang amisusup amora nikâ rawitnya, mengĕt juga ya tan kemur awitnya.

Oøk hier ziet men weder, hoe de vertaler de bedoeling van het origineel goed begrepen heeft. Omtrent de woordbeteekenissen blijkt nog, dat tatan anggâ, dat gewoonlijk beteekent "ongenegen zijn, niet willen", hier "onfeilbaar" of Skr. a w a çy a moet beteekenen, terwijl tan kemuran blijkens het verband "zonder zich te vergissen moet beteekenen ${ }^{1}$.

Het laatste vers, dat in dit HS. (cod. 34581) aangehaald wordt is Mahâbhârata, XI, $72^{\mathrm{b}}$ en $73^{\mathrm{a}}$ of Böhtlingk Ind. Spr. 4627:

Bhaiṣajyam etad duḥkasya yad etan nânucintayet, cintyamânaṃ hi na wyeti bhûyaç câpi prawartate.

In de editie leest men in plaats van prawartate prawardhate (neemt toe). De O. Jav. vertaling is: Nyang prasiddha tambâ ning prihati, kramanya, ikang wastu hilang, lunghâ, mâti,

1 Zie ook dr. van der Tunk's Kawi-Balineesch Woordenboek, I, p. 385, s. v. 
tan siddha kârjjananya kunang, ya tikâ tan angĕn-angĕnĕn, âpan apagěh rakĕt nikâ ri hati yan inangĕı-angĕn, rumakĕt pwa ya ${ }^{1}$; mangkin awuwuh kramanya, ya tânuwuhakĕn prihati, matangnyan haywa ikâ inangĕn-angĕn.

De vertaler geeft, zooals men ziet, eene omschrijving van pribati, de vertaling van duhkha, in de volgende woorden, die ingeleid worden door kramanya. De dubbele negatie in de woorden na wyeti geeft de vertaler weer door het positieve a pag ĕh rakĕt.

Cod. 3458i eindigt met Mahâbhârata, XII, 6763 of Ind. Spr. 6342 :

Çakunânâm yathâkâçe matsyânâm iwa codake padam yathâna ḍ̣çyeta tathâ jñânawidậ̣ gati (̣̣).

In plaats van jñânawidâm leest men bij Böhtlingk, IIl, p. 352 puṇyakrtâm (van de deugdzamen), doch op eene andere plaats (M.Bh. XII, 12156) staat evenals hier jũânawidâm. De O. J. vertaling luidt: Tatan kna linakșaṇan, tanpakatonan, luput winikalpa, jũâna nikâ sang jñânî ngaran ira, kadyangga ning tapak ing manuk anglayang ring âkâça, tan katon tapaknya ring langit, mwang ikan tan katon tapaknya ring wwe.

De Sanskritwoorden $\mathrm{n}$ a dṛ çeta worden dus achtereenvolgens op drie verschillende wijzen weergegeven door den vertaler. Hij gebruikt voor "visch" hetzelfde woord als in het Maleisch.

Het bovenstaande is voldoende, om een denkbeeld te geven van deze spreukenverzameling, die vrij oud moet zijn, zooals blijkt uit de taal. Het is merkwaardig, dat de Sanskritverzen, die in andere Oudjavaansche werken, als het Mahâbhârata, Brahmâṇḍapurânạa en Uttarakâṇạ, meestal zoo corrupt zijn, hier zoo goed bewaard zijn gebleven.

\footnotetext{
1 Hier eindigt cod. 34581. Het volgende is aangehaald uit cod. $3458 \mathrm{i}$.
} 